\title{
LOCATION OF PLASTIC HINGES IN AXIALLY LOADED STEEL MEMBERS
}

by Brian H. H. Peng ${ }^{1}$, Gregory A. MacRae ${ }^{2}$, Warren R. Walpole
Peter $^{3}$,

\begin{abstract}
New Zealand and Australian steel structure design standards contain equations to encourage yielding at the ends of steel members rather than along their lengths. This paper evaluates the accuracy of these equations using a commercially available computer program as well as an analytical procedure. The analytical procedure considers non-linear geometric effects and material effects of the member stiffness by considering stability functions in conjunction with residual stress effects. New equations to prevent yielding away from the member ends, which are less conservative than the current code equations, are developed. Simplifications of these equations being considered for adoption into the New Zealand steel structure design standard are described.
\end{abstract}

\section{INTRODUCTION}

The New Zealand and Australian steel codes (SNZ, 1997; SAA, 1975) have a check that is not present in the codes of many other countries. This check aims to restrict the formation of plastic hinges away from the ends of the columns. That is, they desire the bending moment diagram to be that in Figure 1a, rather than that in Figure 1b. This is because:

i) the region beside the plastic hinges can be effectively braced to restrict local and laterally buckling to ensure inelastic rotational deformation capacity is not decreased, and

ii) the correct collapse mechanism and hinge rotation demands may be predicted (Lay, 1975).

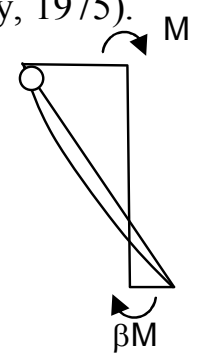

(a) Plastic Hinge at Member End

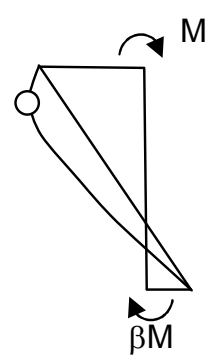

(b) Plastic Hinge within Member Length

Figure 1. Moment Patterns for Different Hinge Positions (based on Lay, 1975)

\footnotetext{
${ }^{1} \mathrm{PhD}$ Candidate, University of Canterbury, Christchurch, New Zealand

${ }^{2}$ Associate Professor, University of Canterbury, Christchurch, New Zealand

${ }^{3}$ Senior Lecturer, University of Canterbury, Christchurch, New Zealand

${ }^{4}$ Senior Engineer, New Zealand Heavy Engineering Research Association, Manukau City, NZ

${ }^{5}$ Director, Steel Construction New Zealand, Manukau City, NZ
} 
The tendency for hinges to occur within the member length rather that at the member ends is dependent on three parameters: firstly, the axial force ratio, $N^{*} / N_{s}$, where $N^{*}$ is the applied axial force and $N_{s}$ is the section axial yield force; secondly, the ratio of the member end moments, $\beta$, which is computed as the smaller absolute moment divided by the larger absolute moment where positive means double curvature; and thirdly the slenderness of the member which is often represented by $\lambda$, a non-dimensional factor given by Equations 1 and 2 for members with compact sections, where $N_{O L}$ is the Euler buckling force, $k$ is the effective length factor, $L$ is the actual length of the member, $r$ is the radius of gyration about the axis of bending, $\sigma_{Y}$ is the material yield stress, and $E$ is Young's modulus for steel. Furthermore, the magnitudes of the moments are also important if the member is to yield.

$$
\begin{aligned}
\lambda \quad & =\sqrt{\frac{N_{S}}{N_{O L}}} \\
& =\frac{k L}{\pi r} \sqrt{\frac{\sigma_{Y}}{E}}
\end{aligned}
$$

Clause 8.4.3.2 in NZS 3404 (SNZ, 1997) specifies that for members with various slenderness and moment ratios, that the axial force ratio, $N^{*} /\left(\phi N_{s}\right)$, be given by Equations 3 and 4, where $\phi$ is the resistance factor. These are referred to as Lay's equations. A plot of the permitted $N^{*} /\left(\phi N_{s}\right)$, for a particular slenderness limit, $\lambda$, and moment ratio, $\beta$, based on Equations 3 and 4 is given in Figure 2. It can be seen that there is a discontinuity at the axial force ratio of 0.15 .

$$
\begin{array}{ll}
\frac{N^{*}}{\phi N_{S}} \leq\left[\frac{1+\beta-\lambda}{1+\beta+\lambda}\right] & \text { when } \frac{N^{*}}{\phi N_{S}}>0.15 \\
\frac{N^{*}}{\phi N_{S}} \leq\left[\frac{0.6+0.4 \beta}{\lambda}\right]^{2} & \text { when } \frac{N^{*}}{\phi N_{S}} \leq 0.15
\end{array}
$$




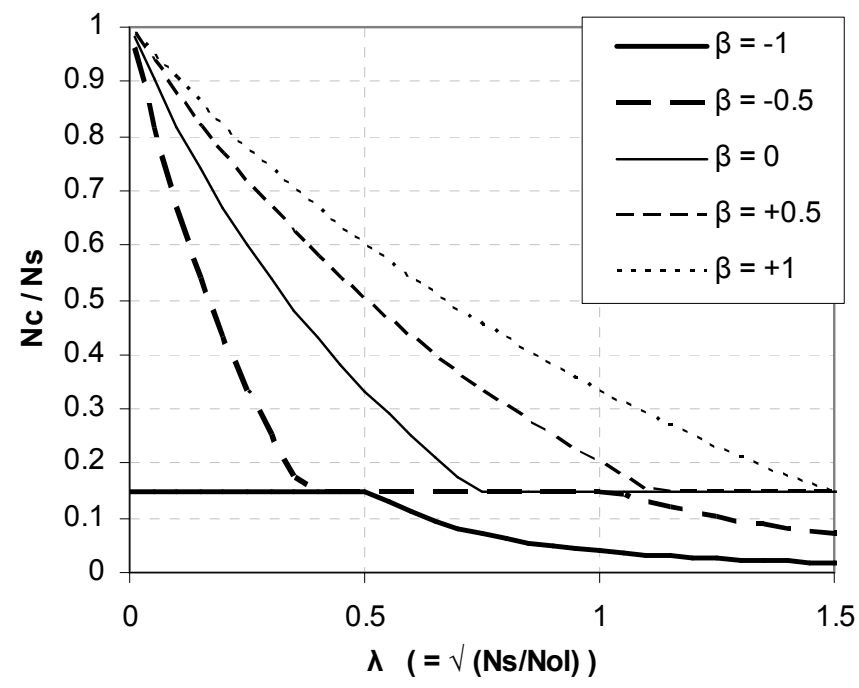

\section{Figure 2. Axial Force Limits for Different Member Slenderness and End Moment Ratio}

For axial force ratios, $N^{*} /\left(\phi N_{s}\right)$, greater than 0.15 , the source book (Lay, 1975) states that Equation 3 is adopted by curve fitting the column deflection curve data in Lay's $\mathrm{PhD}$ thesis for high axial load members, in conjunction with an analytical approach to keep the hinges away from the member ends. It is also developed to guarantee rotation capacity, but the degree of rotation capacity provided by these equations is not described. Lay's thesis (Lay, 1964) does present this equation for the case of $\beta=0$, but the exact means by which the equation was developed was not clear, and the comparison of the data and the equation were not shown.

For low axial force ratios, that is when $N^{*} /\left(\phi N_{s}\right)$ is less than 0.15 , Equation 4 was developed from elastic stability considerations with the maximum moment in the column being limited to less than 1.05 of the design moment at the column ends. The equation is then linearized for easy application. The value of 1.05 indicated that for these members with low axial forces, yielding is permitted to occur away from the member ends. Lay argues that this is reasonable because these members act as beams due to their low axial force, and yielding away form the member ends is not likely to be detrimental. It should be noted that in this equation when $\beta$ is unity, indicating double curvature, the axial force ratio in Equation 4 is limited by Euler buckling alone.

The New Zealand steel code (SNZ, 1997) has provisions to ensure rotation capacity of a hinge at the end of the member by providing limitations on the axial force ratio. For this reason, other equations are not needed to provide rotation capacity as well as to ensure that yielding occurs at the member end, but they are only required to ensure that yielding occurs at the member end.

Based on the discussion above it may be seem that the background for Equation 3 is not clear; it is not apparent how reasonable this equation is to prevent end yielding; there is an undesirable discontinuity in Lay's equations; the approach to obtain the two equations is different; and the NZ code already has criteria for ensuring 
deformation capacity if the yielding occurs at the column end. Therefore, there is a need to evaluate Lay's equations to determine how well they describe when yielding is likely to occur away from, rather than at, the column ends, and to develop new equations if these are found to be inadequate.

Two different analysis tools were used to evaluate the reasonableness of the end yielding criteria (EYC) in Lay's equations. A computer program 'Dr. Frame' (Dr. Software, 1998) was used for the case when the column was elastic, and an analytical approach was developed considering stability functions and the effect of residual stresses on the member flexural stiffness.

\section{MODEL DEVELOPMENT}

\section{Dr. Frame Analysis}

The analysis tool 'Dr. Frame' (Dr. Software, 1998) is capable of performing a second or higher order analysis using the correct stability functions for axial tension and compression using real-time analysis and visual updating. It also reduces the flexural stiffness of the member due to axial force as a result of residual stresses and out-ofstraightness using information from the AISC column curve (AISC 2005).

In order to determine the axial force ratio at which the maximum member moment moves away from the member ends as a function of end moment ratio, $\beta$, and slenderness, $\lambda$, the following approach was used. A simply supported member was set-up as shown in Figure $\mathbf{3}$ and the members were provided with specific member properties. The 'Second Order Geometric Effects' were selected and the Resistance Factors' were turned off, under 'Modeling' tool bars. The 'EI Dependency' was turned off for the elastic analysis. The end moments were then applied for a specified end moment ratio, $\beta$. The magnitude of the moment is not important. The member length, $L$, was then chosen such that the initial member slenderness, $\lambda$, is 0.1 . A small axial force was initially applied. It was gradually increased until the maximum moment moves away from the member ends. This was easily identified because the bending moment diagram is calculated instantaneously by the program as shown in Figure 3. The axial force when moment just moves away from the member end is recorded. At this stage the axial force may be increased further until the member becomes unstable giving the Euler buckling force of the member. The process above was repeated for different lengths incrementing $\lambda$ by 0.1 each time until a value of 5 is reached. This gives relationship between $N^{*} / N_{s}$ and $\lambda$ for a chosen end moment ratio. The process was repeated to obtain relationships for end -moment ratios, $\beta$, of -1.0 , $0.5,0.0,+0.5$ and +1.0 . If inelastic behavior is desired based on the AISC column curve, then the process can be repeated by turning on the 'EI Dependency'. However, instead of the Euler buckling curve, the AISC column strength curve is obtained when the member become unstable. 


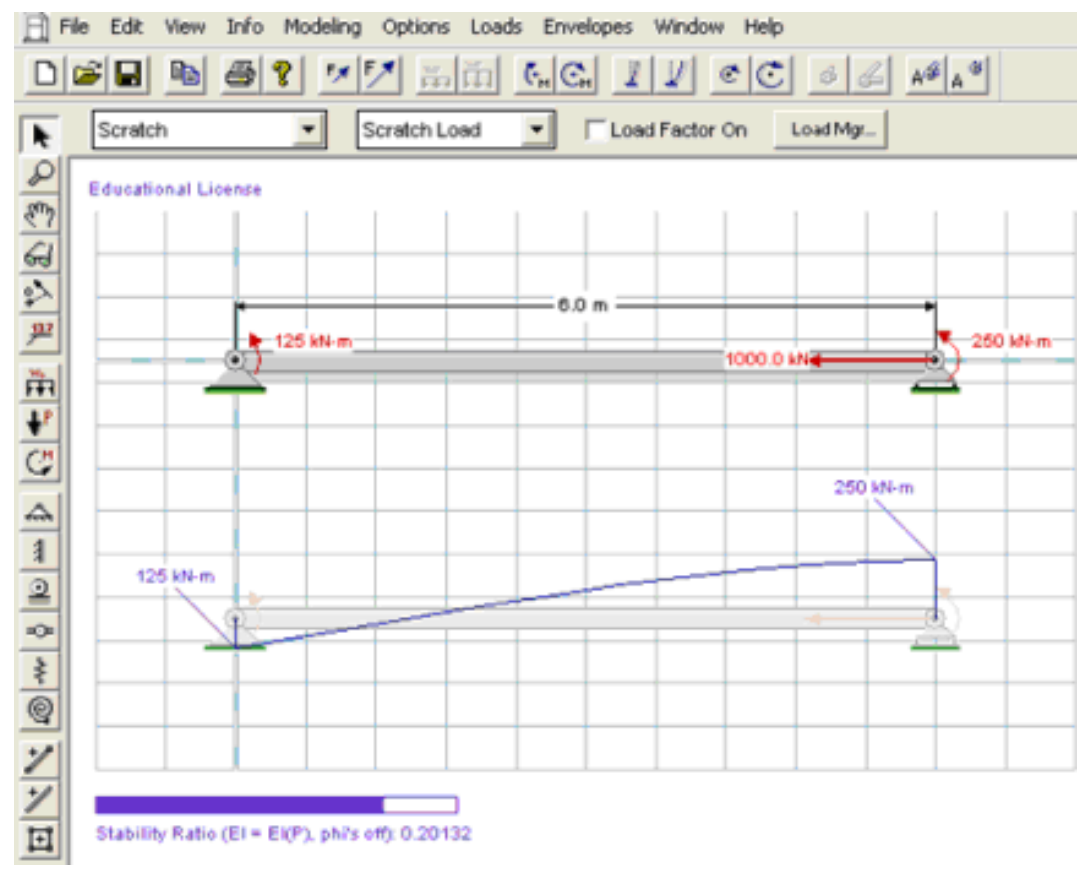

Figure 3. Dr. Frame Window Interface

\section{Analytical Model}

The analysis tool was developed from first principles to independently evaluate Lay's equations. This model allowed consideration of the residual stress and out-ofstraightness assumed for columns in the New Zealand/Australian codes which are different than that assumed in the US code (AISC, 2001). The model was derived based on stability functions which consider the reduction in stiffness from the axial force due to geometric nonlinearity. The inelastic flexural stiffness of member was also incorporated in the model to consider the reduction in stiffness from the axial force due to material nonlinearity, which mainly due to residual stress effects on the member according to tangent stiffness buckling theory. The tool was developed using the computer program 'MATLAB' (MATLAB, 2005). Description about the stability function and inelastic stiffness approaches used are given below:

\section{(a) Beam-Column Stability Functions}

For a uniform steel column member such as that shown in Figure 4, when the effect of compressive axial force is considered on elastic column stiffness the relationship between lateral displacement at end $\mathrm{A}, v_{A}$, lateral displacement at end $\mathrm{B}, v_{B}$, rotation at end $\mathrm{A}, \theta_{A}$, rotation at end $\mathrm{B}, \theta_{B}$, to the shear force at end $\mathrm{A}, V_{A}$, shear force at end $\mathrm{B}$, $V_{B}$, moment at end A, $M_{A}$ and moment at end $\mathrm{B}, M_{B}$ is given in $4 \times 4$ matrix form in Equation 5 (MacRae, 1999) where $I$ is the column second moment of area. 


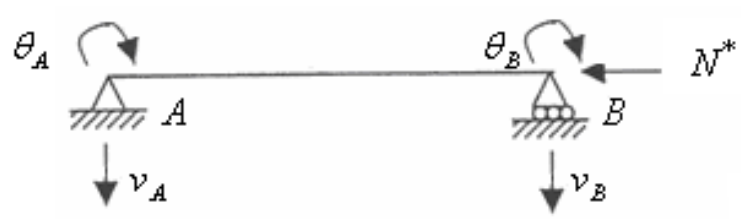

Figure 4. Beam-Column Member

$$
\begin{aligned}
E I & {\left[\begin{array}{cccc}
f / L^{2} & g / L & -f / L^{2} & g / L \\
g / L & s & -g / L & r \\
-f / L^{2} & -g / L & f / L^{2} & -g / L \\
g / L & r & -g / L & s
\end{array}\right]\left\{\begin{array}{c}
v_{A} \\
\theta_{A} \\
v_{B} \\
\theta_{B}
\end{array}\right\}=\left\{\begin{array}{c}
V_{A} \\
M_{A} \\
V_{B} \\
M_{B}
\end{array}\right\} } \\
\text { where } \quad r & =\frac{\phi^{2}-\phi \sin \phi}{2(1-\cos \phi)-\phi \sin \phi} ; \\
s & =\frac{\phi(\sin \phi-\phi \cos \phi)}{2(1-\cos \phi)-\phi \sin \phi} \\
g & =s+r ; \\
f & =2(s+r)-\phi^{2} \\
\phi & =\sqrt{N^{*} L^{2} / E I}
\end{aligned}
$$

If the member is broken into two parts as illustrated in Figure 5 where $L_{1}<<L_{2}$, and the moment applied at node $\mathrm{A}$ is greater than that at node $\mathrm{C}$, then the moment at node $\mathrm{B}, M_{B}$, may be found using the following approach. The stability matrices for each sub-member can be combined to form a global stiffness matrix as shown in Equation 11 which is a $4 \times 4$ matrix as $v_{A}$ and $v_{C}$ in Figure 5 are zero. As the externally applied moments at $\mathrm{A}$ and $\mathrm{C}$ are specified, and the external forces at $\mathrm{B}$ are equal to zero, the deformation terms may be found. These deformations can then be fed back into a $3 \times 3$ sub-member stiffness matrix, such as that in Equation 12, to obtain $M_{B}$. The axial force which causes the maximum moment to move away from the supports may be identified as that which causes $M_{B}$ to be greater than $M_{A}$. A sensitivity study (Peng et al. 2006) showed that when $L_{l}$ is less than $0.01 L$, the axial force causing the moment to move is not sensitive to $L_{l}$ but the computational analysis time became excessive as $L_{1}$ became smaller so $L_{1}$ was taken as $0.01 \mathrm{~L}$. Also, the axial force required to cause the determinant of the total member stiffness matrix to be zero was equal to the total member Euler buckling load for a range of sub-member lengths thereby verifying the matrix formulation above.

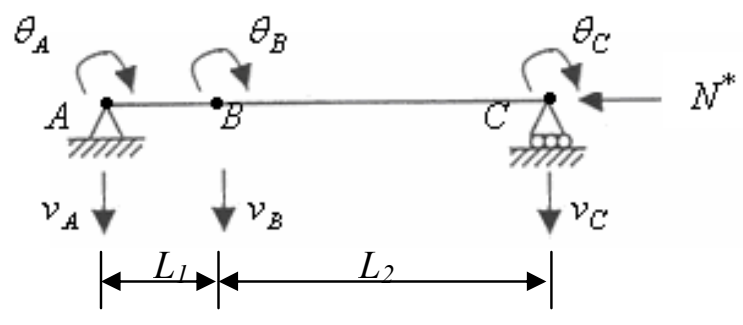

Figure 5. Member with Two Internal Degrees of Freedom 


$$
\begin{aligned}
& E I\left[\begin{array}{cccc}
s_{1} / L_{1} & 0 & -g_{1} / L_{1}^{2} & r_{1} / L_{1} \\
0 & s_{2} / L_{2} & g_{2} / L_{2}^{2} & r_{2} / L_{2} \\
-g_{1} / L_{1}^{2} & g_{2} / L_{2}^{2} & f_{1} / L_{1}^{3}+f_{2} / L_{2}^{3} & -g_{1} / L_{1}^{2}+g_{2} / L_{2}^{2} \\
r_{1} / L_{1} & r_{2} / L_{2} & -g_{1} / L_{1}^{2}+g_{2} / L_{2}^{2} & s_{1} / L_{1}+s_{2} / L_{2}
\end{array}\right]\left\{\begin{array}{l}
\theta_{A} \\
\theta_{C} \\
v_{B} \\
\theta_{B}
\end{array}\right\}=\left\{\begin{array}{c}
M_{A} \\
M_{C} \\
V_{B} \\
M_{B}
\end{array}\right\} \\
& \frac{E I}{L_{1}}\left[\begin{array}{ccc}
s_{1} & -g_{1} / L_{1} & r_{1} \\
-g_{1} / L_{1} & f_{1} / L_{1}^{2} & -g_{1} / L_{1} \\
r_{1} & -g_{1} / L_{1} & s_{1}
\end{array}\right]\left\{\begin{array}{l}
\theta_{A} \\
v_{B} \\
\theta_{B}
\end{array}\right\}=\left\{\begin{array}{l}
M_{A} \\
V_{B} \\
M_{B}
\end{array}\right\}
\end{aligned}
$$

(b) Effect of Axial Force on Flexural Stiffness and Buckling Force

Tangent stiffness buckling theory is used to determine the effective flexural stiffness, $(E I)_{t}$, of a member subject to axial force as a result of section inelasticity. This theory recognizes the effects of residual stresses on the behaviour. For example, a steel section with the stress distribution shown in Figure 6(b) is likely to have an average stress-average strain diagram as shown in Figure 7. It may be seen that the tangent stiffness decreases as the axial force increases as a result of yielding at points (i) to (iv) as shown in Figure 8. In this figure the thicker line corresponds to yielding of the section. This reduction in axial stiffness indicates that buckling is more likely to occur than if the section remains elastic.

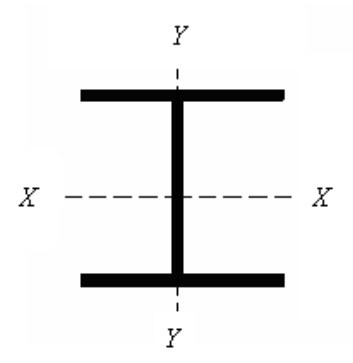

(a) Steel I-section

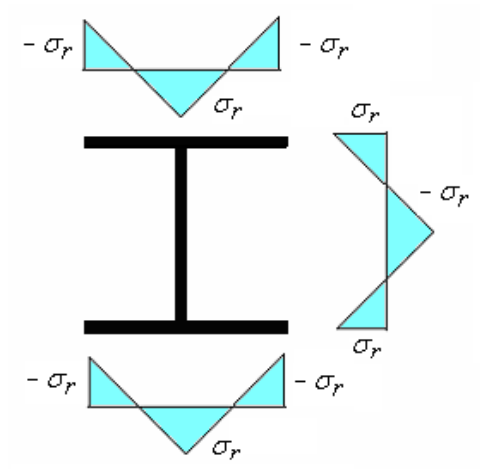

(b) Typical initial residual stress pattern

Figure 6. Steel Cross-Section Axes and Initial Stresses

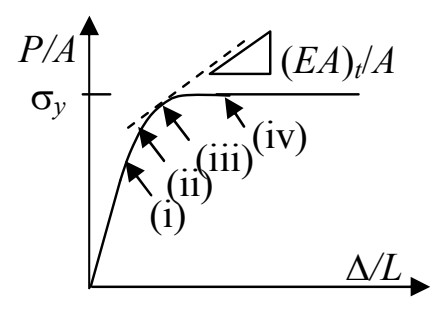

Figure 7. Schematic Axial Average Stress $(P / A)$ - Average Strain $(\Delta L)$ Plot 


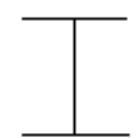

(i)

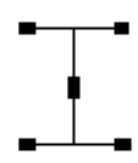

(ii)

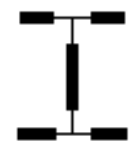

(iii)

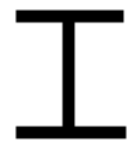

(iv)

Figure 8. States of Yielding at Different Applied Axial Compressive Forces

The bending stiffness, EI, also reduces as the axial force on the section increases as shown in Figure 9. The tangent stiffness for an elastic-perfectly plastic (EPP) material is given by Equation 13 where $I_{e}$ is the second moment of area for the elastic portion of the section about the bending axis considered.

$$
(E I)_{t}=E I_{e}
$$

Figure 9(a) shows that the effect of the yielding would be expected to cause a more rapid decrease in bending resistance about the weak axis, rather than about the strong axis, as the weak axis second moment of area, $I_{y e}$, is more sensitive to yielding at the extremities of the flanges, than is $I_{x e}$ as shown in Figure 9(b).

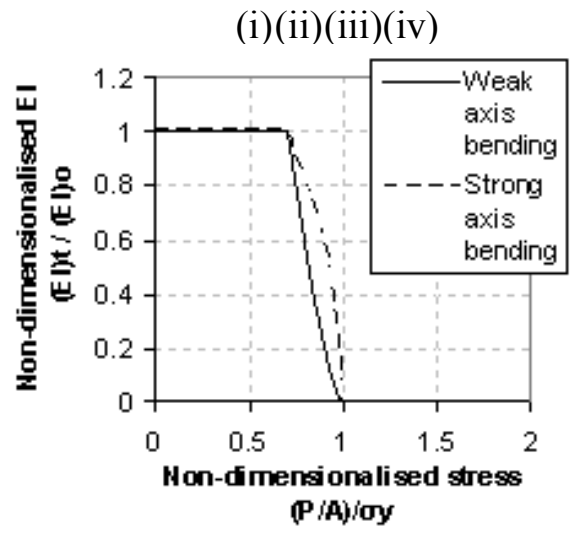

(a) Idealised tangent flexural stiffness

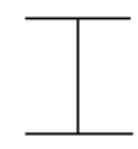

(1)

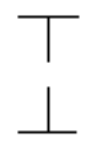

(ii)

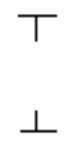

(iii) (iv)

Figure 9. Schematic Axial Stress Effect on Tangent Fexural Stiffness

The concept of the effective stiffness may be used to develop a column design curve for member under axial compression. That is the column buckling curve for an inelastic column, $N_{c}$, can therefore be written according to Equation 14 which is the same equation used to obtain the Euler buckling strength, $N_{O L}$, except that $(E I)_{t}$ rather than $(E I)$ is used, where $(E I)_{t}$ is a function of the axial force level and the axis of buckling. This is the dark curve in Figure 10. It may be seen that the inelastic buckling curve has a lower strength for a given effective length than does the elastic buckling curve.

$$
N_{c}=\frac{\pi^{2}(E I)_{t}}{(k L)^{2}}
$$




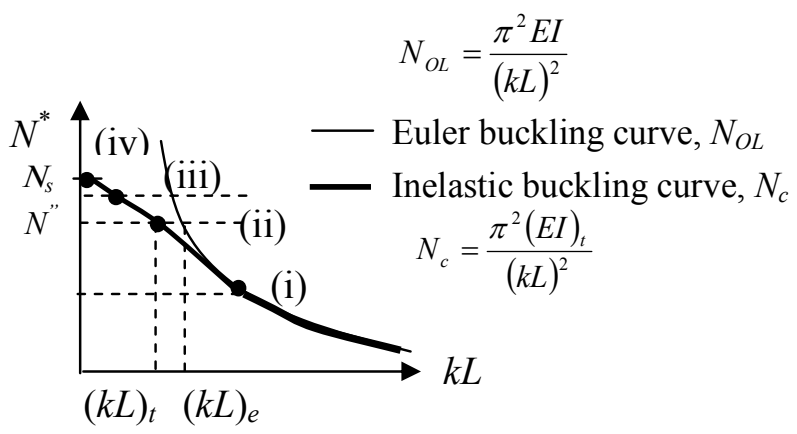

Figure 10. Schematic of Inelastic and Elastic Buckling Curves for a Steel Column

If the effective flexural stiffness, $(E I)_{t}$, were known it could be used with the stability equations to determine when the maximum moment moves away from the column end. Unfortunately, it is usually not directly available. However, because the column design curve, which is often a similar shape to the inelastic curve shown in Figure 10 is known, it is possible to use the difference between the column design curve and the Euler buckling curve to evaluate $(E I)_{t}$ as a function of axial force. This can be carried out using the following information.

At a specific axial compressive force, $N$, the effective lengths corresponding to the inelastic and elastic buckling curves, $(k L)_{t}$ and $(k L)_{e}$, are given by Equations 15 and 16 respectively.

$$
\begin{aligned}
& (k L)_{t}=\sqrt{\frac{\pi^{2}(E I)_{t}}{N^{\prime \prime}}} \\
& (k L)_{e}=\sqrt{\frac{\pi^{2} E I}{N^{\prime \prime}}}
\end{aligned}
$$

In general, the value of $(k L)_{e}$ for the axial force level, $N$ ", may be computed, and these values of $(k L)_{t}$ for the axial force level, $N$ ", may be obtained from a design code for a specific section type. In this case, the effective stiffness, $(E I)_{t}$, may be computed from Equation 17. The effective stiffness could equally well be obtained from the ratio of $(k L / r)$ squared or $\lambda$ squared because the length is just scaled by a constant in these cases.

$$
(E I)_{t}=E I\left(\frac{(k L)_{t}}{(k L)_{e}}\right)^{2}
$$

For the New Zealand steel code, there are 5 column buckling curves for different types of section, described by section constants, $\alpha_{b}$, as shown in Figure 11. These curves not only consider the initial residual stress effect but also the effect of member out-of-straightness and accidental non-concentric loading. Consequently, $(E I)_{t}$ values 
based on these curves will be underestimated compared to that for residual stresses only. Hence, the analytical model derived in this study, which based on the New Zealand column design curves, is likely to be more conservative than if these effects are not being included.

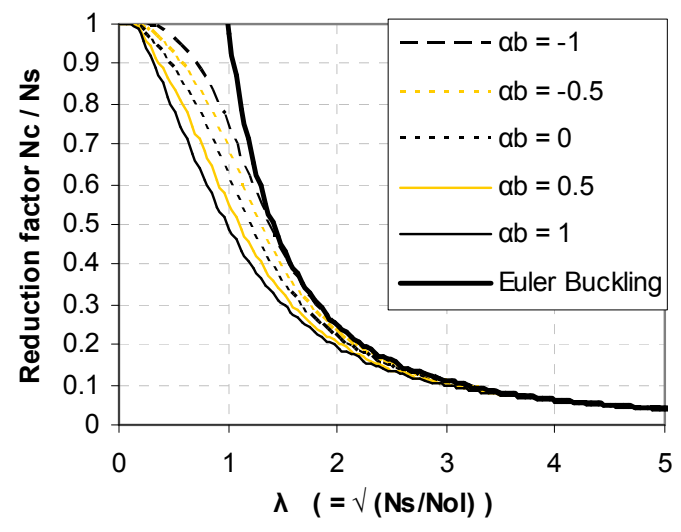

Figure 11. Elastic and Inelastic Column Curve in NZS 3404

\section{(c) Analysis Procedure}

The analysis procedure used to determine the axial force that will cause yielding away from the member ends for a specific column and moment ratio is iterative considering the reduction in member stiffness due to both geometric (stability function) and material (residual stress) nonlinearity. Firstly, a member is chosen with particular characteristics described by the parameters $L, A_{s}, \sigma_{y}, E, I, \alpha_{b}$ and $\beta$. Then a low axial force, $N$, is chosen. For this axial force, the effective stiffness, $(E I)_{t}$, is computed using Equation 17 for the specific column curve selected. Here, $(k L)_{t}$ is obtained by iteration because it cannot be obtained explicitly from the NZ code equations. Next, the effective stiffness is used in the stability equations as described previously to determine whether or not $M_{B}$ is greater than $M_{A}$ in Figure 5 indicating that the maximum moment had moved away from the end of the member. If $M_{B}$ is less than $M_{A}$ then the axial load is gradually increased until it is. The axial force corresponding to this situation is the critical force for that member and moment ratio. Analyses were carried out for many different section slendernesses, the 5 column types and for different moment ratios.

The analytical model was checked against Dr. Frame and the Euler buckling curve to ensure that it modelled the Euler buckling curve well. The analytical method to evaluate the axial force associated with movement of the peak moment away from the member end was also verified successfully against Dr. Frame for the inelastic case.

\section{ANALYTIC ESTIMATES AND COMPARISONS}

The axial force levels that cause the maximum moment to occur away from the member ends are shown in a form similar to that of Figure 2 in Figure 12 for different moment ratios, $\beta$. It may be seen that:

(i) Lay's equations (from NZS 3404) tend to be conservative for members with axial force ratios greater than 0.15 . 
(ii) Lay's equations tend to be non-conservative for members with axial force ratios less than 0.15 . This is to be expected because the equations were developed assuming that the member moment be no more than 1.05 times the end moment.

(iii) The column buckling curves from the analyses are continuous, and therefore more rational than Lay's equations which have a discontinuity at an axial force ratio of 0.15 .

(iv) The results from Dr. Frame matched the analysis. The difference arises where Dr. Frame is based on LRFD curve and the analytical model is base on NZS 3404 column curves.

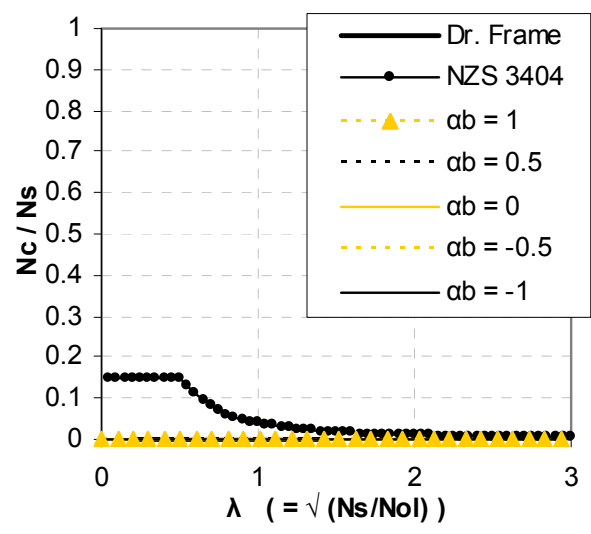

(a) $\beta=-1$

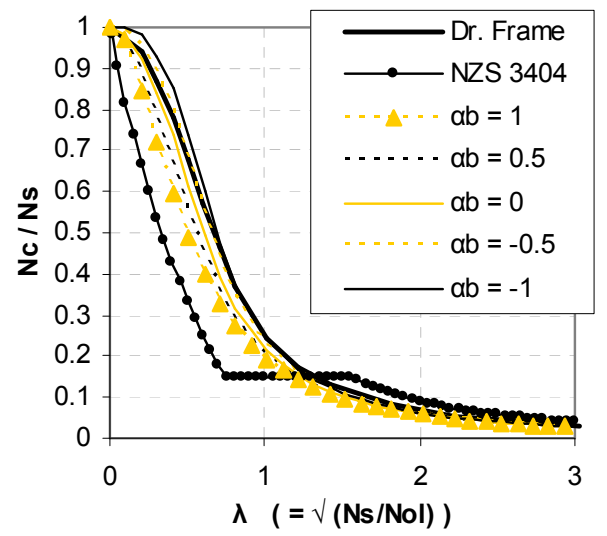

(c) $\beta=0$

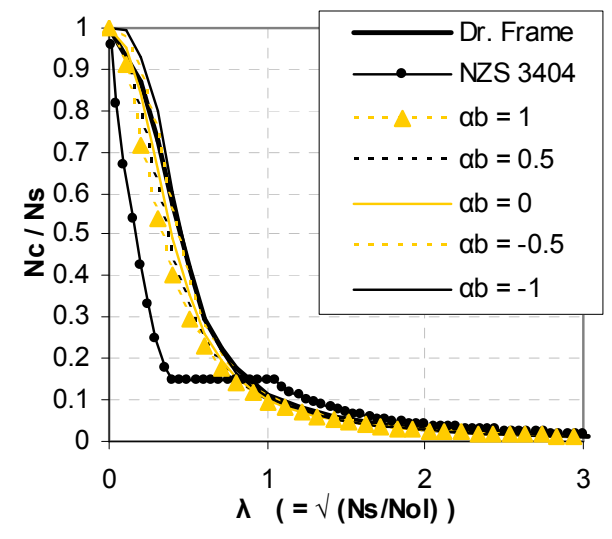

(b) $\beta=-0.5$

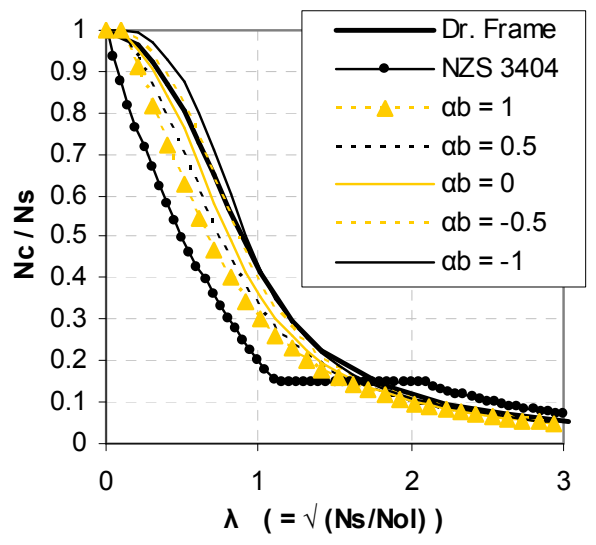

(d) $\beta=+0.5$ 


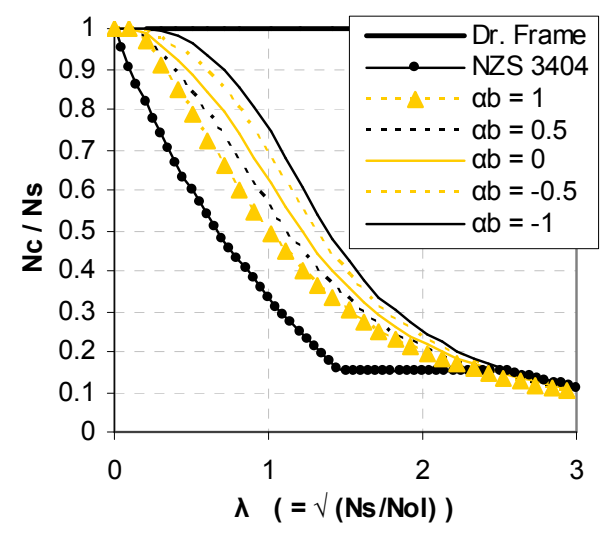

(e) $\beta=+1$

Figure 12 - Comparison of NZS 3404, MATLAB and Dr. Frame for Different Moment Ratios $\beta$

\section{Proposed End Yielding Equation and Amendments to NZS 3404}

There is no closed form for the curves given in Figure 12. Empirical equations are therefore developed for the end yielding criteria, EYC, to make the information more useful to designers. Regression with an exponential function was used to obtain Equation 18. Three parameters are required in this EYC equation. These vary with column types with different residual stresses, $\alpha_{b}$, as shown in Table 1.

$$
\frac{N_{C}}{N_{S}} \leq\left\{\frac{A \times(\beta+1)^{B}}{e^{(C / \beta+1)}}\right\}^{\lambda}
$$

Table 1. Coefficients for Column Types

\begin{tabular}{|c|c|c|c|}
\hline$\alpha_{\mathrm{b}}$ & $A$ & $B$ & $C$ \\
\hline 1 & 0.235 & 0.95 & 0.21 \\
\hline 0.5 & 0.247 & 0.91 & 0.19 \\
\hline 0 & 0.263 & 0.88 & 0.19 \\
\hline-0.5 & 0.265 & 0.92 & 0.17 \\
\hline-1 & 0.276 & 0.87 & 0.19 \\
\hline
\end{tabular}

It may be seen in Figure 13 that the proposed equation is generally more conservative than the analysis results, especially for columns with axial force ratio greater than 0.5 . As $\beta$ approaches 1, the shape of the EYC curve is harder to be fitted using an exponential function. Subsequently, the conservatism in the proposed equation increases for more highly axial loaded members. However, it should be noted that the axial force ratio is usually less than 0.5 for a general column. Hence, the proposed equation would provide suitable limits within the normal design range.

The proposed equations are much closer to the actual EYC curves than is NZS 3404. Adoption of the proposed equations would reduce the conservatism on column size in the current design guidelines. In addition, the proposed equation does not have a discontinuity. 


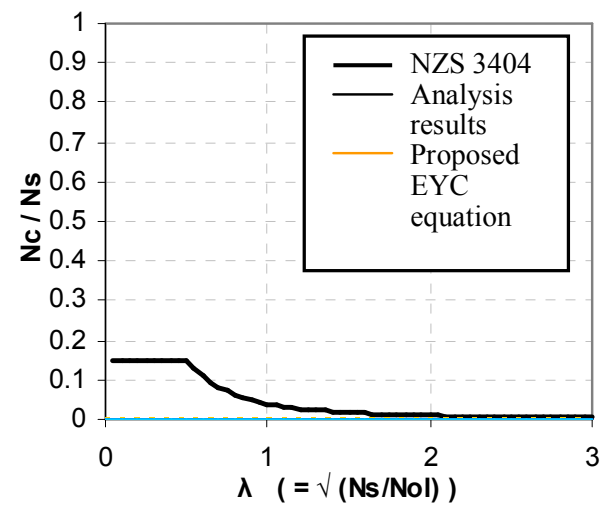

(a) $\beta=-1$

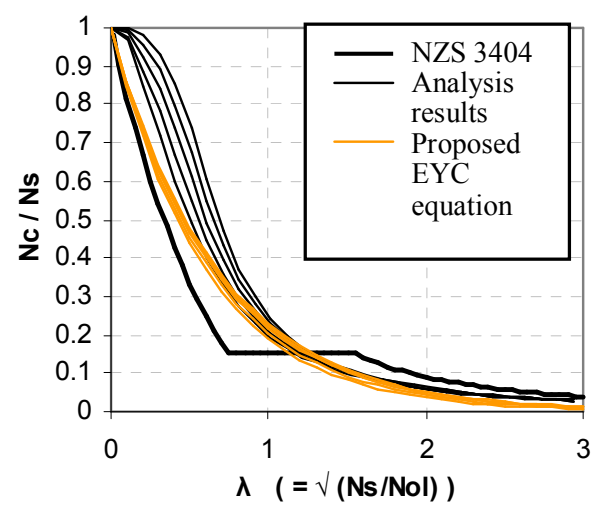

(c) $\beta=0$

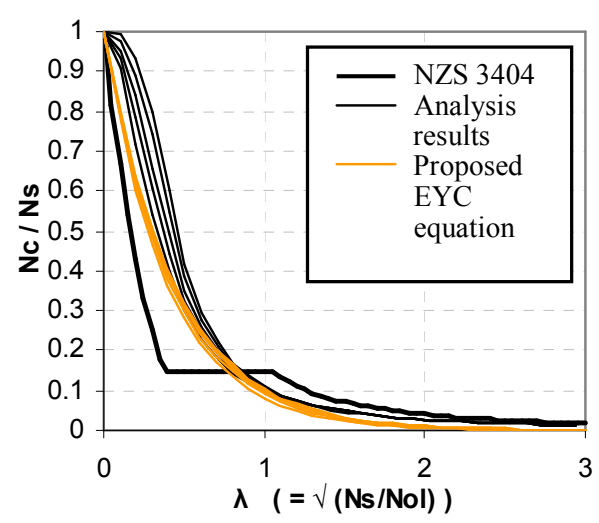

(b) $\beta=-0.5$

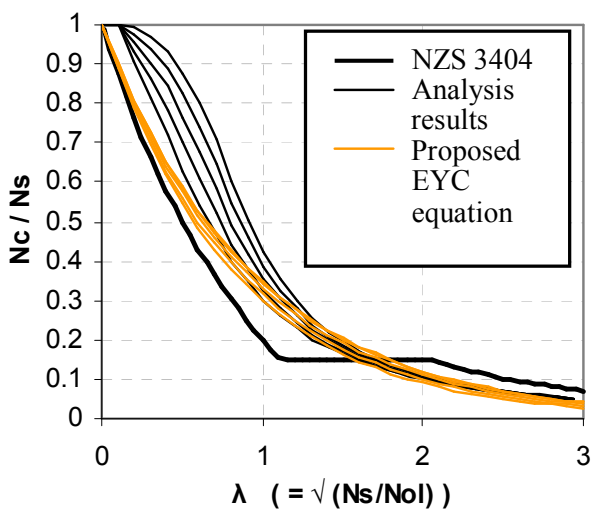

(d) $\beta=+0.5$

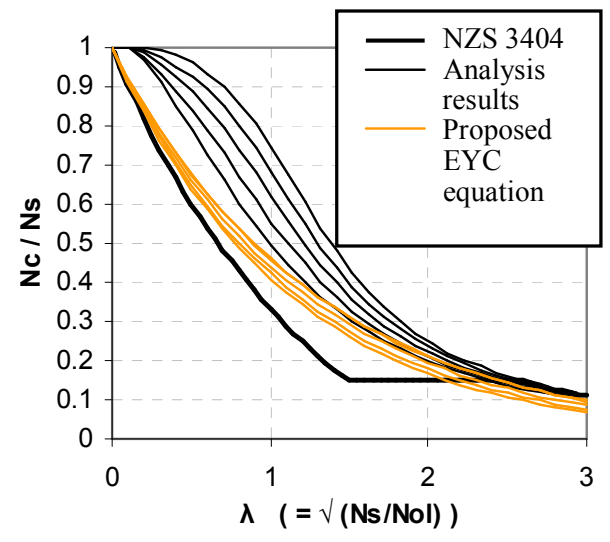

(e) $\beta=+1$

Figure 13. Comparison of NZS 3404, Analysis Results and Proposed EYC Equation for Different $\beta$

Clifton suggests (Peng et al. 2006) that for design purposes the EYC equation be simplified further and that $\alpha_{b}$ be considered to be zero for all column types resulting in Equation 19. This is non-conservative for negative $\alpha_{b}$ values as seen in Figure 12 especially for high axial forces, but this non-conservatism may balance the conservatism in Equation 19 for high axial forces. Equation 19 is still more conservative than the Lay's equations for low axial forces. 


$$
\frac{N^{*}}{\phi N_{s}} \leq\left\{\frac{0.263(\beta+1)^{0.88}}{e^{\left(\frac{0.19}{\beta+1}\right)}}\right\}^{\lambda}
$$

\section{CONCLUSIONS}

Procedures are developed considering both geometric and material non-linearity effects on the column stiffness to determine the level of axial force that causes yielding to occur away from, rather than at the ends of steel columns. It was found that:

1. Current New Zealand and Australian steel structure design standard equations generally significantly underestimate the axial force corresponding to yielding occurring away from, the member end, for columns with compressive axial force ratios greater than 0.15. However, the design standard equations for columns with lower axial forces are generally overestimated. This currently results in conservative designs for columns with high axial forces, and nonconservative designs for columns with low axial forces.

2. New design equations were proposed to describe the level of axial force corresponding to migration of the location of the plastic hinge away from the member end. These equations do not contain a discontinuity, as current design standard equations do, and they significantly better match the expected behaviour. These equations are likely to result in smaller column sizes than those obtained with current codes.

\section{ACKNOWLEDGEMENTS}

Financial for this project provided by the Steel Construction New Zealand, SCNZ, and Heavy Engineering Research Association, HERA, and the University of Canterbury is gratefully acknowledged. All opinions expressed in this paper are those of the authors and they do not necessarily represent those of the sponsors.

\section{REFERENCES}

AISC. 2001. "Manual of Steel Construction, Load and Resistance Factor Design", American Institute of Steel Construction, 3nd Ed., Chicago, USA.

Dr. Software. 1998. "Dr. Frame 2D." Dr. Software, LLC, Seattle, USA.

Lay, M. G. 1964. "The Static Load Deformation Behaviour of Planar Steel Structures," PhD Thesis, Lehigh University, Bethlehem, USA.

Lay, M. G. 1975. Source book for the Australian steel structures code - AS 1250, Australian Institute of Steel Construction, Sydney.

MacRae, G. A. 1999. CEE513 Advanced Steel Structures, Postgraduate Course Notes, University of Washington, USA.

MATLAB, 2005, The MathWorks, Inc., Natick, MA, USA

Peng B. H. H., MacRae G. A., Walpole W. R., Moss P., Dhakal R. 2006. " Plastic Hinge Location in Columns of Steel Frames", Department of Civil Engineering, University of Canterbury, Civil Engineering Research Report Number to be Assigned.

SAA. 1975. SAA Steel Structures Code AS 1250, Standards Association of Australia, Sydney, Australia. 
SNZ. 1997. Steel structures standard NZS 3404, Standards New Zealand, Wellington, NZ. 